\title{
Effect of Crosslink Density on Cut and Chip Resistance of 100\% SBR Based Tire Tread Compound
}

\author{
KASI ELANGOVAN*, FRANCIS XAVIER JOSEPHRAJ ${ }^{2}$, ARUN KUMAR MURUGESAN ${ }^{1}$, \\ BALU PANDIAN ${ }^{3}$ \\ ${ }^{1}$ Department of Rubber and Plastics Technology, Madras Institute of Technology Campus, Anna University, Chennai- \\ 600044, Tamil nadu, India \\ ${ }^{2}$ School of Mechanical Engineering, VIT Bhopal University, Bhopal, Madhya Pradesh, 466114 \\ ${ }^{3}$ Department of Automobile Engineering, Bharath Institute of Higher Education and Research, Chennai
}

\begin{abstract}
The effect of Crosslink density on Cut and Chip resistance was affected on a typical 100 percent styrene-butadiene rubber (SBR)-based tire tread compound. In order to successfully develop products for tires used in off-road or poor roads and other demanding rubber applications, it is important to understand the $C \& C$ effect in rubber. Crosslink density varied by varying the sulphur to the accelerator ratio and also by changing the process aids. Basic polymer, filler and other ingredients such as activators and anti-degradants have remained unchanged. In the first setup, the sulphur was kept constant and the accelerator varied and the reverse was done in the second setup. It was made to achieve different crosslink density by changing the oil dosage and adding different resins. An attempt has been made to correlate Cut and Chip resistance to other physical properties. All these tests have been identified and optimized by the traditional tire tread compound.
\end{abstract}

Keywords: Cut and Chip resistance, crosslink density, off-the road, tire tread, cure system

\section{Introduction}

The use of giant tires in off-the road systems (OTR), such as tractor, grader, backhoe, front end loader, etc., is routinely to be heavily cut and chipped when used in areas not accessible by traditional concrete or asphalt paths. Cutting happens when a sharp object hits a surface with sufficient force to penetrate and cut the surface [1]. The chipping of the rubber compound is generally tearing at $90^{\circ}$ to the cutting direction, due to the effect of the traction, braking and other forces on raw or sharp surfaces. Cutting and Chipping causes the tire tread to tearing away the big chips. Cutting happens unexpectedly, without tearing; chipping is relatively sudden, but also with tear force. Neither cutting nor chipping has to do with the propagation of crack or propagation of fatigue [2].

Applications where the $\mathrm{C} \& \mathrm{C}$ resistance is important include mining agriculture off-the road tires, light-duty all-terrain truck tires and low road heavy-duty lorry tires [3]. A tire enters into contact with a wide variety of surfaces and textures, and the tread is subjected to intense asperities, while the tire is transmitted by a contact pad to complex vehicle forces [4]. Although $C \& C$ is complex, conventional C\&C laboratory test methods use simple devices that do not alter load conditions significantly and the only information obtained from the test sample is the loss of weight [5-6]. Rubber surfaces exposed to strenuous, slipping effects bear large normal stresses that can lead to damage and eventual removal from the surface of material. Typical scenarios are tire treads on rugged terrain, agricultural or military track system service and hard granular material conveyor belts. For pneumatic applications, such tread rubber cutting and chipping $(\mathrm{C} \& \mathrm{C})$ activity is a major concern when the tires are in contact with dirt, rocks, and rough ground surfaces, whether off-the road or in bad road conditions [7]. The usual difficulties in predicting $\mathrm{C} \& \mathrm{C}$ resistance of tire treads from the tests of rubber compounds in the laboratory are often appropriate to resort to costly research programmes involving the iterative tire building and field testing of new researchers [8].

A distinct correlation was found between the chemical crosslink structures and the mechanical properties, which, in turn, promoted the formation of the crosslink density of the rubber.

*email: *elangok@mitindia.edu 
The tensile strength slightly increased when the accelerator content was higher. In particular, the relative tensile strength and the elongation at break sharply increased by adding the secondary accelerators. In other words, the chemical crosslink characterizations were affected by the accelerator content, and these subsequently influenced the rubber's mechanical properties. The crosslink characterizations can be adjusted by changing the accelerator rather than the carbon black to improve the mechanical properties [9]. Good abrasion resistance was not co-relatable with C\&C resistance. In other words, some tread compounds with good abrasion resistance had unsatisfactory $\mathrm{C} \& \mathrm{C}$ resistance; others with good $\mathrm{C} \& \mathrm{C}$ resistance had unsatisfactory abrasion resistance [10]. From these literatures limited work carried out on tire tread compounds. The aim of this work is to study the effect of crosslink density on cut and chip resistance of $100 \%$ sbr based tire tread compounds on typical tire tread compounds. In addition, the crosslink density varied by varying the sulphur to the accelerator ratio and also by changing the process aids.

\section{Materials and methods}

Rubber compounding with known chemicals in order to achieve the desired properties to the raw SBR rubber is formulated by adding chosen chemicals with control formulation of a typical OTR tire tread. It had been clearly found out that there may be a chance for agglomeration of filler materials inside matrix material due to improper dispersion that may result in stress concentration, which could be eluded by proper mixing [11], so due care has been made while mixing the ingredients into rubber. Master batch were prepared in a Banbery with a temperature of $160^{\circ} \mathrm{C}$ for $4 \mathrm{~min}$ by combining the rubber and other ingredients except curatives. The curing agents were then added to a two-rolling mill for 5 min in a laboratory and the final batch compounds were prepared [12].

To create crosslink at molecular level and thus to improve strength and elasticity, cross-linking agents are required. Uncured rubbers have low elasticity and strength, like a high molecular weight polymers [13]. By formulating long-chain molecules, networks are formed and the substance from a viscous fluid into an elastic solid. It's what takes place during vulcanization or cross-linking that increases strength, modulus and hysteresis. As a vulcanization agent, sulphur is commonly used in formulation. The input energy is retained by a deformed elastomer in terms of elastic potential energy [14]. It is released after crack growth and serves as the driving force for splitting. By molecular movements, the remainder of the energy is dispersed into liquid. Due to its high cross-link levels, a strong network of the molecular chain limited the chain motion, preventing the network from disappearing most of the energy that causes a fracture with low extension. Too high crosslinks are unwanted and may cause brittle fractures and may not be robust enough to survive viscous flow failure [15].

The optimal interlink density range for practical use needs therefore to be determined [16]. The rubber compound strengthening agents act as stress stoppers and must have a highly specific area. The particle therefore needs to be less than 1 micron in size. Carbon black and silica are popular fillers. The primary particle size can be obtained up to $0.1 \mu \mathrm{m}$, which gives a certain area of a few hundred $\mathrm{m}^{2}$ per gram [17]. Table 1 showed the formulation of rubber compounds.

\subsection{Cure Characteristics of Rubber Compounds}

The cure characteristics of rubber compounds were studied on a MDR at $190^{\circ} \mathrm{C}$ as per ASTM D2084-07. From the graphs, the optimum Cure time and scorch time could be determined. Rubber specimens for various physical testing including the Cut and chip test were prepared by mixing the ingredients by two stages [18]. 
Table 1. Formulation of the Rubber Compounds

\begin{tabular}{|c|c|c|c|c|c|c|c|c|c|c|c|c|c|c|c|}
\hline \multicolumn{16}{|c|}{ Formulation of the Rubber Compounds } \\
\hline & \multicolumn{15}{|c|}{ FORMULATION NO } \\
\hline & EX1 & EX2 & EX3 & EX4 & EX5 & EX6 & EX7 & EX8 & EX9 & $\begin{array}{c}\mathbf{E X} \\
\mathbf{1 0}\end{array}$ & \begin{tabular}{c|}
$\mathbf{E X}$ \\
$\mathbf{1 1}$ \\
\end{tabular} & $\begin{array}{c}\mathbf{E X} \\
12 \\
\end{array}$ & $\begin{array}{c}\mathbf{E X} \\
\mathbf{1 3} \\
\end{array}$ & $\begin{array}{l}\text { EX } \\
14 \\
\end{array}$ & $\begin{array}{l}\mathbf{E X} \\
15 \\
\end{array}$ \\
\hline INGREDIENTS & \multicolumn{15}{|c|}{ CONTENT IN phr a } \\
\hline SBR-1502 & 100 & 100 & 100 & 100 & 100 & 100 & 100 & 100 & 100 & 100 & 100 & 100 & 100 & 100 & 100 \\
\hline CARBON BLACK & 60 & 60 & 60 & 60 & 60 & 60 & 60 & 60 & 60 & 60 & 60 & 60 & 60 & 60 & 60 \\
\hline PROCESS OIL & 7.0 & 7.0 & 7.0 & 7.0 & 7.0 & 7.0 & 7.0 & 7.0 & 7.0 & 7.0 & 7.0 & 7.0 & 7.0 & 3.0 & 11 \\
\hline ZINC OXIDE & 4.0 & 4.0 & 4.0 & 4.0 & 4.0 & 4.0 & 4.0 & 4.0 & 4.0 & 4.0 & 4.0 & 4.0 & 4.0 & 4.0 & 4.0 \\
\hline STEARIC ACID & 2.0 & 2.0 & 2.0 & 2.0 & 2.0 & 2.0 & 2.0 & 2.0 & 2.0 & 2.0 & 2.0 & 2.0 & 2.0 & 2.0 & 2.0 \\
\hline $\begin{array}{c}\text { ZINC SOAP OF } \\
\text { UNSATURATED FATTY } \\
\text { ACIDS } \\
\end{array}$ & 1.0 & 1.0 & 1.0 & 1.0 & 1.0 & 1.0 & 1.0 & 1.0 & 1.0 & 1.0 & 1.0 & 1.0 & 1.0 & 1.0 & 1.0 \\
\hline $\begin{array}{c}\text { PHENOLIC TACKIFIER } \\
\text { RESIN }\end{array}$ & 2.5 & 2.5 & 2.5 & 2.5 & 2.5 & 2.5 & 2.5 & 2.5 & 2.5 & 2.5 & 2.5 & 2.5 & 2.5 & 2.5 & 2.5 \\
\hline PROCESS AID & - & - & - & - & - & - & - & - & - & - & - & - & - & 4.0 & - \\
\hline GUM RESIN & 3.5 & 3.5 & 3.5 & 3.5 & 3.5 & 3.5 & 3.5 & 3.5 & 3.5 & 3.5 & 3.5 & 3.5 & 3.5 & 3.5 & - \\
\hline MICROCRYSTALLINE WAX & 2.0 & 2.0 & 2.0 & 2.0 & 2.0 & 2.0 & 2.0 & 2.0 & 2.0 & 2.0 & 2.0 & 2.0 & 2.0 & 2.0 & 2.0 \\
\hline TMQ & 1.0 & 1.0 & 1.0 & 1.0 & 1.0 & 1.0 & 1.0 & 1.0 & 1.0 & 1.0 & 1.0 & 1.0 & 1.0 & 1.0 & 1.0 \\
\hline 6PPD & 2.2 & 2.2 & 2.2 & 2.2 & 2.2 & 2.2 & 2.2 & 2.2 & 2.2 & 2.2 & 2.2 & 2.2 & 2.2 & 2.2 & 2.2 \\
\hline SOLUBLE SULPHUR & 1.4 & 1.4 & 1.4 & 1.4 & 1.4 & 1.4 & 0.8 & 1.1 & 1.4 & 1.7 & 2.0 & 1.4 & 1.4 & 1.4 & 1.4 \\
\hline TBBS & 0.7 & 1.0 & 1.2 & 1.4 & 1.6 & 1.8 & 1.0 & 1.0 & 1.0 & 1.0 & 1.0 & 1.0 & 1.0 & 1.0 & 1.0 \\
\hline MBTS & 0.3 & 0.3 & 0.3 & 0.3 & 0.3 & 0.3 & 0.3 & 0.3 & 0.3 & 0.3 & 0.3 & 0.3 & 0.3 & 0.3 & 0.3 \\
\hline PVI & 0.1 & 0.1 & 0.1 & 0.1 & 0.1 & 0.1 & 0.1 & 0.1 & 0.1 & 0.1 & 0.1 & 0.1 & 0.1 & 0.1 & 0.1 \\
\hline HARDENER RESIN & - & - & - & - & - & - & - & - & - & - & - & - & 3.0 & - & - \\
\hline
\end{tabular}

${ }^{\mathrm{a}} \mathrm{phr}$ - Parts per Hundred parts of Rubber

\subsection{Determination of Laboratory Cut and Chip Resistance}

The determination of cut and chip resistance was made using the B. F. Goodrich tester, for which the schematic diagram is shown in Figures 1 and 2. The frequency of the stroke of the cut and chip indentor was $1 \mathrm{~Hz}$, and the rotation speed of the rubber wheel was set to be 750rpm. The corresponding speed at the surface of rubber wheel is about $1.25 \times 10^{5} \mathrm{~mm} / \mathrm{min}$. The diameter loss Di was measured for $20 \mathrm{~min}$, and the loss was divided by the number of strokes $\mathrm{n}$ to represent the average rate of cut and chip per stroke Rcc. This value was adopted as the measure of cut and chip characteristics [19-20]. The radial impact force Fi was constant for each stroke. Thus, the frictional force Ff will be different for each rubber compound, depending on its frictional characteristics (Figure 2). The surface temperature of the sample was found to rise rapidly during the cut and chip experiment; that is, it rose from room temperature to about $50^{\circ} \mathrm{C}$ just $2 \mathrm{~min}$ after the starting of the experiment. The final temperatures of black-filled natural rubber (FNR) and black-filled polybutadiene (FBR) were 55 to $65^{\circ} \mathrm{C}$, respectively [21]. 


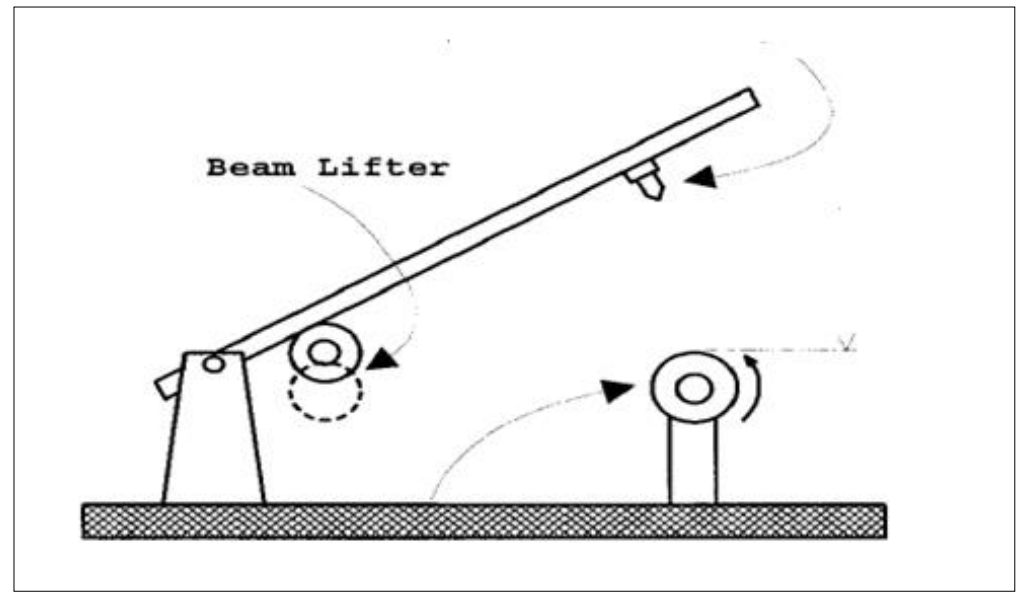

Figure 1. A Sketch of the B.F Goodrich cutting and chipping tester

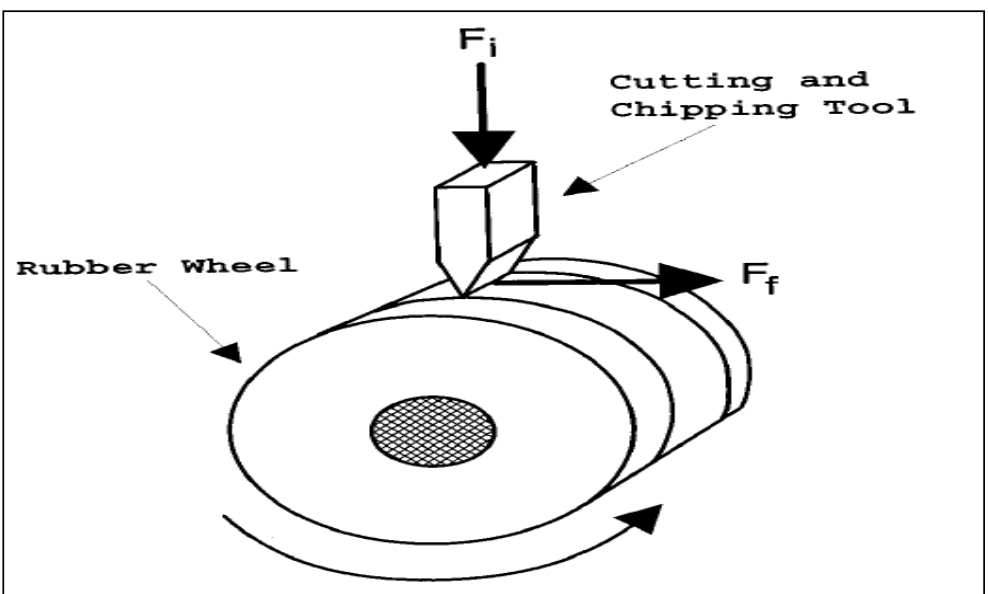

\author{
Specification \\ Model: Tungsten Carbide Impactor \\ Width (w):6.3mm \\ Thickness (T): 15-20 microns \\ Drop Height (h): $47 \mathrm{~mm}$ \\ Rubber Wheel for \\ Diameter: $50 \mathrm{~mm}$ \\ Width: $12.5 \mathrm{~mm}$
}

Figure 2. A Sketch of the cutting and chipping part and acting forces of the B.F Goodrich cutting and chipping tester

\title{
2.3 Evaluation of Field Cut and Chip Performance
}

Two tread compounds based on the natural rubber (NR) 100 and NR-butadiene rubber (BR) 80/20 rubbers as in Table 2 were selected for the field tire test. The test tires of 11R22.5 in size for heavy-duty truck were then built using the selected compounds. The test tires were run on a rural road (about $20 \%$ paved), and the worn surfaces were investigated for an appropriate time interval [22].

\subsection{Crosslink Density}

The cross-link density was determined by immersing a small amount (known mass) of sample in $50 \mathrm{~mL}$ of toluene for 3 days to attain equilibrium swelling. After this, the sample is taken out from the toluene and the solvent is blotted from the surface of the sample and is weighed immediately. This sample is then dried out at $70^{\circ} \mathrm{C}$ to constant weight. Then the chemical cross-link density is calculated (as per ASTM D 6814-02) by using the Flory-Rehner equation [23-24].

Table 2. Rubber formulations

\begin{tabular}{|l|c|c|c|c|}
\hline & & SBR & NR & BR \\
\hline \multirow{3}{*}{ Master Batch } & E-SBR 1500 & 98.5 & - & - \\
\cline { 2 - 5 } & SMR20 NR & - & 98.5 & - \\
\cline { 2 - 5 } & High-Cis Nd-BR & - & 49 & 98.5 \\
\cline { 2 - 5 } & N330 CB & 49 & 1.8 & 49 \\
\cline { 2 - 5 } & Zinc oxide & 1.8 & 1 & 1 \\
\hline
\end{tabular}




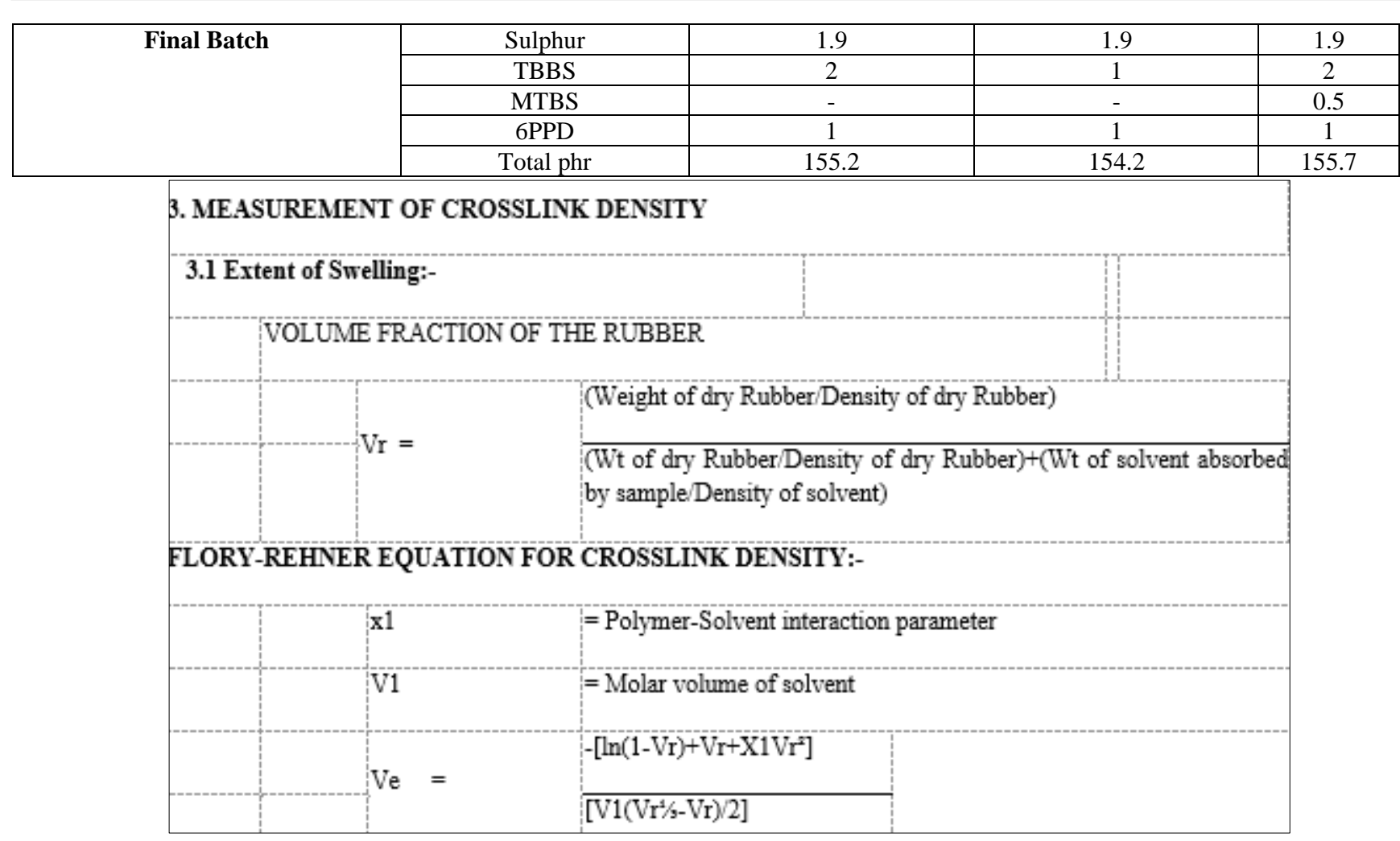

\subsection{Abrasion Resistance}

Abrasion test was done on the DIN abrasion tester for determining the abrasion resistance of compounds of vulcanized rubber, recommended by the Indian Standards Institution vide IS:3400 (Part 3)-1987.The mixed rubber compounds were cured by the compression molding machine at $155^{\circ} \mathrm{C}$ for $40 \mathrm{~min}$. Two specimens from each of the 15 compounds were molded and then tested for obtaining the abrasion loss for each of the samples. The average of all the above parameters was recorded [25-26].

\subsection{Experimental}

A standard tester and test procedure as described in [4] is used in this study for CCC dynamic characterization. The principal scheme of BCCT is shown in Figure 1. Rotating at a set frequency between 0.25 and $2 \mathrm{~Hz}$, eccentric 1 lifts and drops an arm 2 with a precision edge tungsten carbide knife 3 mounted on the end of the arm. The knife impacts a rubber disc sample 4 mounted on a rotating shaft; sample rotation speed is $200-1000 \mathrm{rpm}$. An air cylinder 5 lifts the knife arm at the completion of a preselected test time. The test specimens consist of compression molded rubber cylinders, $5.08 \mathrm{~cm}$ diameter, $1.27 \mathrm{~cm}$ wide, with a $1.27 \mathrm{~cm}$ concentric hole at the center. Test pieces are prepared by compression molding. In contrast with standard application of BCCT, results of CCC characterization are recorded as functions of time. Thus, the wear process for each compound in terms of weight loss, W, (in $\mathrm{g}$ ) is studied for the duration of $10 \mathrm{~min}$ in $30 \mathrm{~s}$ increments. The first specimen of each compound is tested for $30 \mathrm{~s}$, each next specimen is tested $30 \mathrm{~s}$ longer than the previous one, and so on. The weight change is reported for each specimen after each test duration. The weight of the trimmed test piece is measured to an accuracy of $0.0001 \mathrm{~g}$. A standard tester and test procedure as described in [4] is used in this study for CCC dynamic characterization. The principal scheme of BCCT is shown in Figure 1. Rotating at a set frequency between 0.25 and $2 \mathrm{~Hz}$, eccentric 1 lifts and drops an arm 2 with a precision edge tungsten carbide knife 3 mounted on the end of the arm. The knife impacts a rubber disc sample 4 mounted on a rotating shaft; sample rotation speed is 200-1000 rpm. An air cylinder 5 lifts the knife arm at the completion of a preselected test time. The test specimens consist of compression molded rubber cylinders, $5.08 \mathrm{~cm}$ diameter, $1.27 \mathrm{~cm}$ wide, with a $1.27 \mathrm{~cm}$ concentric hole at the center. Test pieces are prepared by compression molding. In contrast with standard application of BCCT, results of CCC 
characterization are recorded as functions of time. Thus, the wear process for each compound in terms of weight loss, W, (in g) is studied for the duration of $10 \mathrm{~min}$ in $30 \mathrm{~s}$ increments. The first specimen of each compound is tested for $30 \mathrm{~s}$, each next specimen is tested $30 \mathrm{~s}$ longer than the previous one, and so on. The weight change is reported for each specimen after each test duration. The weight of the trimmed test piece is measured to an accuracy of $0.0001 \mathrm{~g}$.

Rubber compounds were prepared with two blending phases in an internal mixer (SYD-2L, Everplast, Taiwan) and the two steps were performed. In the first stage, a $50 \mathrm{rev} / \mathrm{min}$ rotor speed, a $100^{\circ} \mathrm{C}$ temperature mixture and a fill factor of 0.7 have been used to generate a master batch. The rubber was first mixed for 1 min with $\mathrm{CB}$ and mixed over 4 min until the drop temperature was 140 to $150^{\circ} \mathrm{C}$. The rubber was then mixed for $1 \mathrm{~min}$. The master batch then was milled and sheared at $60^{\circ} \mathrm{C}$ with a two roll mill. In the second stage, a rotor speed of $35 \mathrm{rev} / \mathrm{min}$ was used to prepare the final batch at the $60^{\circ} \mathrm{C}$ mixing chamber temperature. The first was to mix the master batch part for $1 \mathrm{~min}$ followed by an addition of the complete curing and mixing system for another 2 min at $100-110^{\circ} \mathrm{C}$ drop temperature. Then a two-roll mill at $60^{\circ} \mathrm{C}$ was used to mix the compound and get the final batch. The final batch was held 24 $\mathrm{h}$ before treatment. At $160^{\circ} \mathrm{C}$ with a moving die rheometer (MDR 3000 Basic, Mon-Tech, Germany), the treatment properties - including time for $90 \%$ final cure state (t90) - were evaluated according to ASTM D 6204. The geometry specimens shown in Figure 2 were moulded with a compression moulding machine (LaBEcon 300, Fontijne Presses, Holland) at a thickness of $12.5 \mathrm{~mm}$ at $160^{\circ} \mathrm{C}$ for $13 \mathrm{~min}(13$ $\min =1 \mathrm{~min}$ by $1 \mathrm{~mm}$ ) according to $90+13 \mathrm{~min} .150 \times 150 \times 2 \mathrm{~mm}$ thick sheets were moulded in compression moulding machine witht $90+2 \mathrm{~min}$ for tensile and tear specimens. Specimens have also been cured for abrasion tests [27-28]. Continuous development of the equipment since the prototype was defined in 2013 [29] has resulted in the current prototype development, and a test was carried out on the rubber specimens by means of the cut and chip analyzer [30] (ICCATM), developed by Coesfeld GmbH, Germany, and distributed in Amériques by Endurica, LLC,USA.

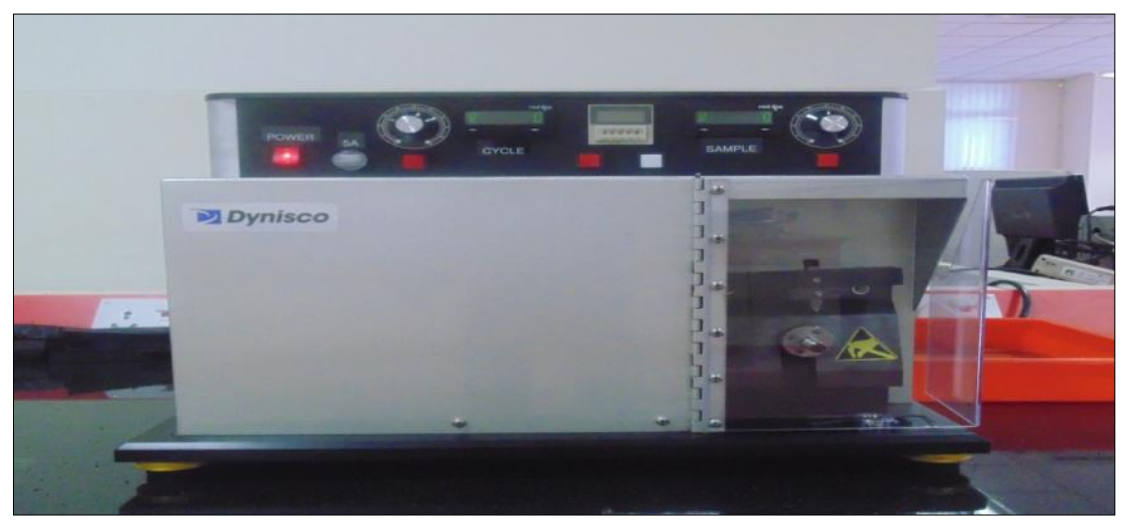

Figure 3. B.F Goodrich cutting and chipping tester

\section{Results and discussions}

\subsection{Physical Properties}

In an attempt to explain the observed results on the cut and chip resistance, some physical properties were also measured for the $100 \%$ SBR based tire tread compounds.

Table 3 and 4 shows the physical properties obtained from the previous tests. Figure 3 and 4 shows the tensile and tear strength of the individual compounds. Figure 4 shows the crosslink density measured by chemical method for all compounds. Also the Cut and Chip resistance was compared to all other properties like crosslink density, Elongation at break, 300\% Modulus and relative volume loss.

As the Accelerator/Activator content was decreased, hardness, stress at $300 \%$ elongation, crosslink density and stress at break decreased considerably. For example, the ultimate tensile strength of a compound was obtained by increased crosslink density [20]. 
Table. 3 Physical Properties of Rubber Compounds

\begin{tabular}{|c|c|c|c|c|c|c|c|}
\hline & $\begin{array}{l}\text { FORMUL } \\
\text { ATION }\end{array}$ & SP.GR & $\begin{array}{c}\text { HARDNESS } \\
\text { (SHORE-A) }\end{array}$ & T.S $\left(\mathrm{kg} / \mathrm{cm}^{2}\right)$ & $\begin{array}{l}\text { EB } \\
(\%)\end{array}$ & $\underset{\left(\mathbf{k g}^{\mathrm{M}} \mathrm{cm}^{2}\right)}{\mathrm{M} 300}$ & $\begin{array}{c}\text { TEAR STRENGTH } \\
(\mathrm{kg} / \mathrm{cm})\end{array}$ \\
\hline \multirow{6}{*}{ 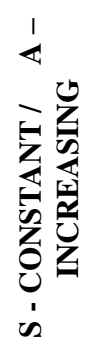 } & EX1 & 1.1475 & 68 & 200 & 614 & 79 & 66 \\
\hline & EX2 & 1.1477 & 71 & 206 & 583 & 90 & 69 \\
\hline & EX3 & 1.1479 & 71 & 206 & 552 & 98 & 70 \\
\hline & EX4 & 1.1480 & 72 & 207 & 525 & 109 & 71 \\
\hline & EX5 & 1.1481 & 72 & 213 & 524 & 110 & 74 \\
\hline & EX6 & 1.1482 & 68 & 214 & 499 & 113 & 74 \\
\hline \multirow{5}{*}{ 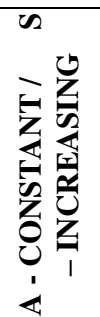 } & EX7 & 1.1461 & 64 & 147 & 722 & 49 & 60 \\
\hline & EX8 & 1.1469 & 71 & 182 & 625 & 73 & 67 \\
\hline & EX9 & 1.1477 & 71 & 206 & 583 & 90 & 69 \\
\hline & EX10 & 1.1486 & 74 & 207 & 491 & 111 & 72 \\
\hline & EX11 & 1.1494 & 74 & 208 & 423 & 134 & 72 \\
\hline \multirow{4}{*}{ 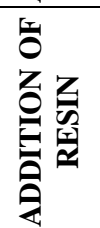 } & EX12 & 1.1477 & 71 & 206 & 583 & 90 & 69 \\
\hline & EX13 & 1.1493 & 75 & 190 & 593 & 88 & 67 \\
\hline & EX14 & 1.1521 & 68 & 215 & 546 & 97 & 64 \\
\hline & EX15 & 1.1438 & 73 & 192 & 630 & 75 & 66 \\
\hline
\end{tabular}

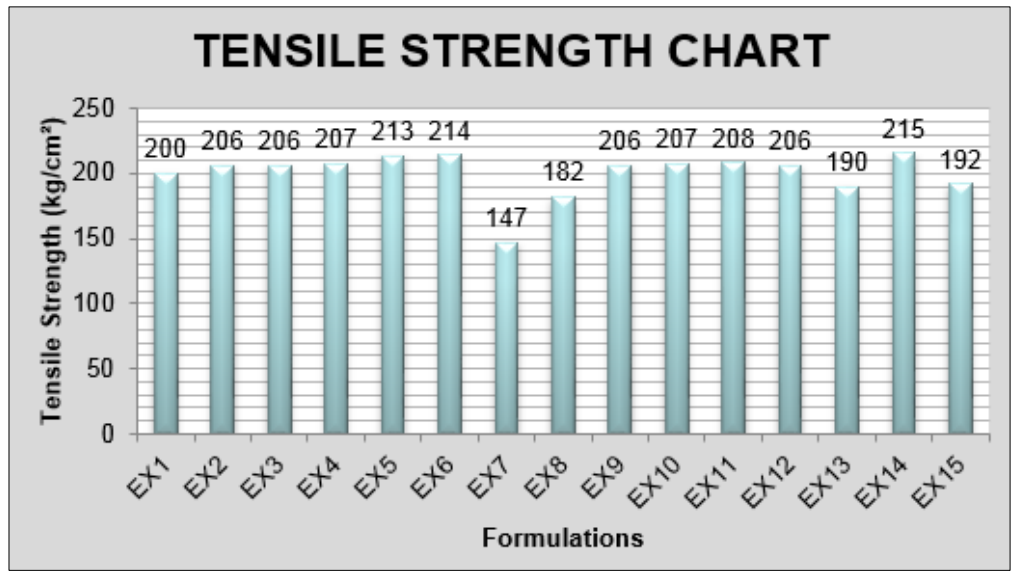

Figure 4. Tensile Strength of the compounds

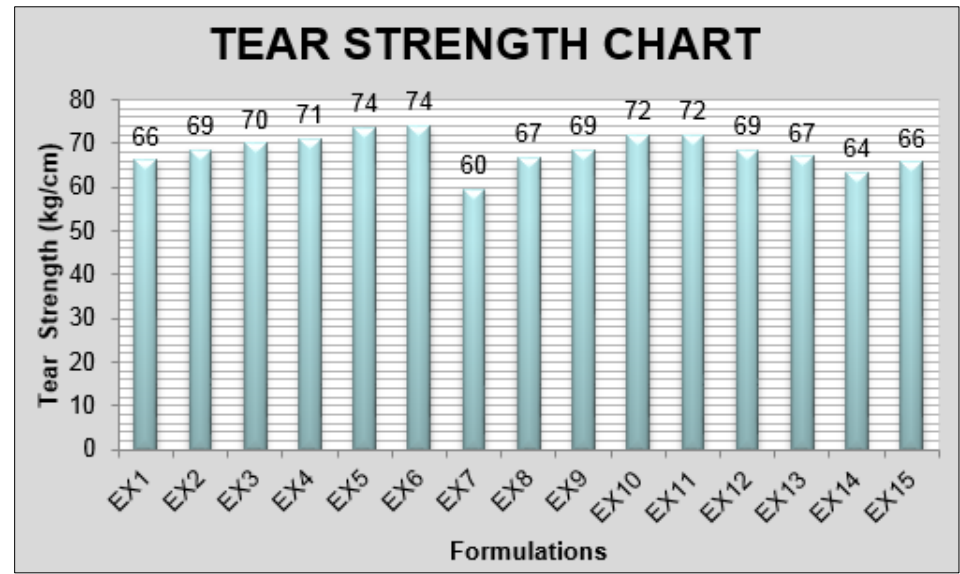

Figure 5. Tear Strength of the compound 
Samples from EX1-EX6, EX7-EX11 shows gradual increase in Tensile and Tear strength with corresponding increase in the curing system, irrespective of whether it is effected by changing Sulphur or Accelerator.

Table 4. Crosslink Density and Volume Loss

\begin{tabular}{|c|c|c|c|c|c|}
\hline & $\begin{array}{c}\text { FORMULA } \\
\text { TION }\end{array}$ & $\begin{array}{c}\text { CROSS LINK } \\
\text { DENSITY (mol/cc) }\end{array}$ & $\begin{array}{l}\text { C\&C VOLUME } \\
\text { LOSS }\left(\mathbf{m m}^{3}\right)\end{array}$ & $\begin{array}{c}\text { RELATIVE } \\
\text { VOLUME LOSS } \\
\left(\mathrm{mm}^{3}\right) \\
\end{array}$ & $\begin{array}{c}\text { REBOUND } \\
\text { RESILIENCE }\end{array}$ \\
\hline \multirow{6}{*}{ 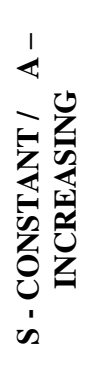 } & EX1 & $3.29 \times 10^{-4}$ & 697 & 145 & 28 \\
\hline & EX2 & $4.28 \times 10^{-4}$ & 800 & 125 & 26 \\
\hline & EX3 & $4.66 \times 10^{-4}$ & 891 & 119 & 25 \\
\hline & EX4 & $4.96 \times 10^{-4}$ & 920 & 117 & 25 \\
\hline & EX5 & $5.21 \times 10^{-4}$ & 950 & 111 & 25 \\
\hline & EX6 & $5.22 \times 10^{-4}$ & 960 & 109 & 27 \\
\hline \multirow{5}{*}{ 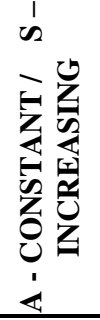 } & EX7 & $2.13 \times 10^{-4}$ & 463 & 163 & 27 \\
\hline & EX8 & $3.29 \times 10^{-4}$ & 664 & 144 & 25 \\
\hline & EX9 & $4.28 \times 10^{-4}$ & 800 & 125 & 26 \\
\hline & EX10 & $5.57 \times 10^{-4}$ & 866 & 122 & 26 \\
\hline & EX11 & $6.64 \times 10^{-4}$ & 983 & 107 & 25 \\
\hline \multirow{4}{*}{ 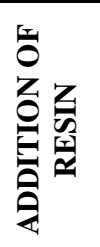 } & EX12 & $4.28 \times 10^{-4}$ & 800 & 125 & 26 \\
\hline & EX13 & $4.19 \times 10^{-4}$ & 813 & 136 & 25 \\
\hline & EX14 & $4.50 \times 10^{-4}$ & 905 & 112 & 28 \\
\hline & EX15 & $3.33 \times 10^{-4}$ & 694 & 138 & 27 \\
\hline
\end{tabular}

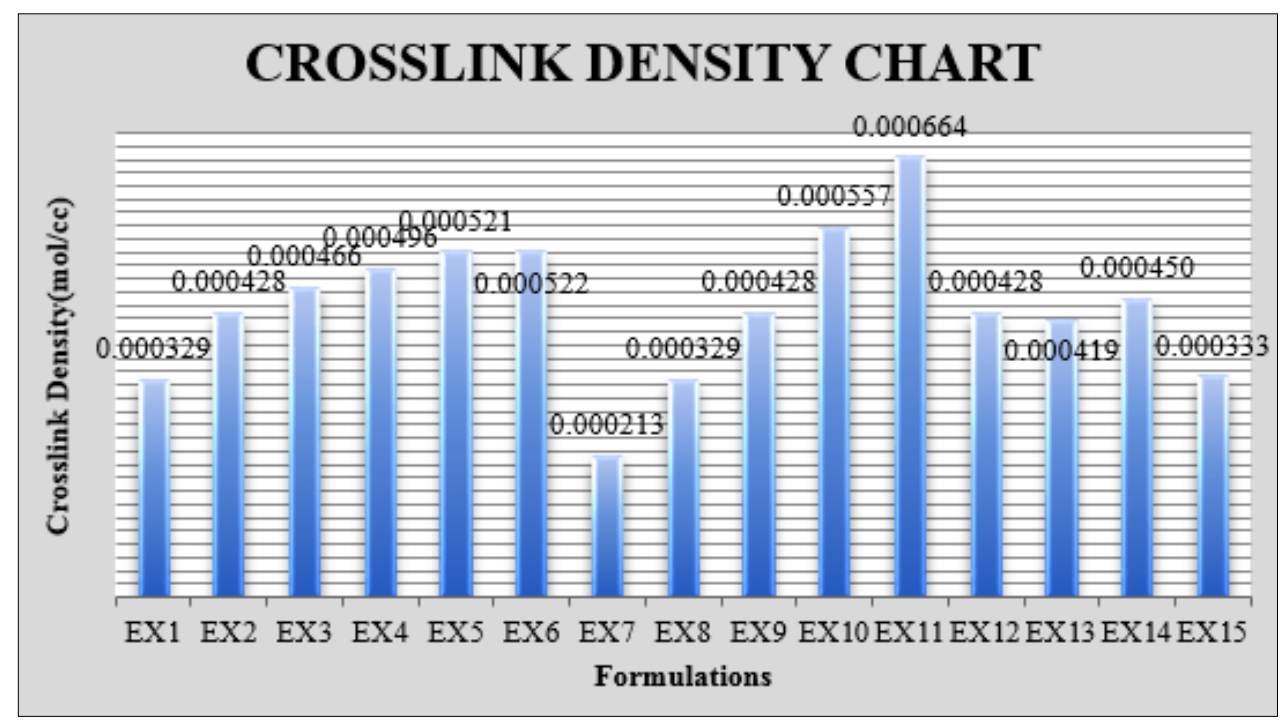

Figure 6. Crosslink Density of the compounds

Samples from EX1-EX6, EX7-EX11 shows gradual increase in crosslink density with corresponding increase in the curing system, irrespective of whether it is effected by changing Sulphur or Accelerator. 


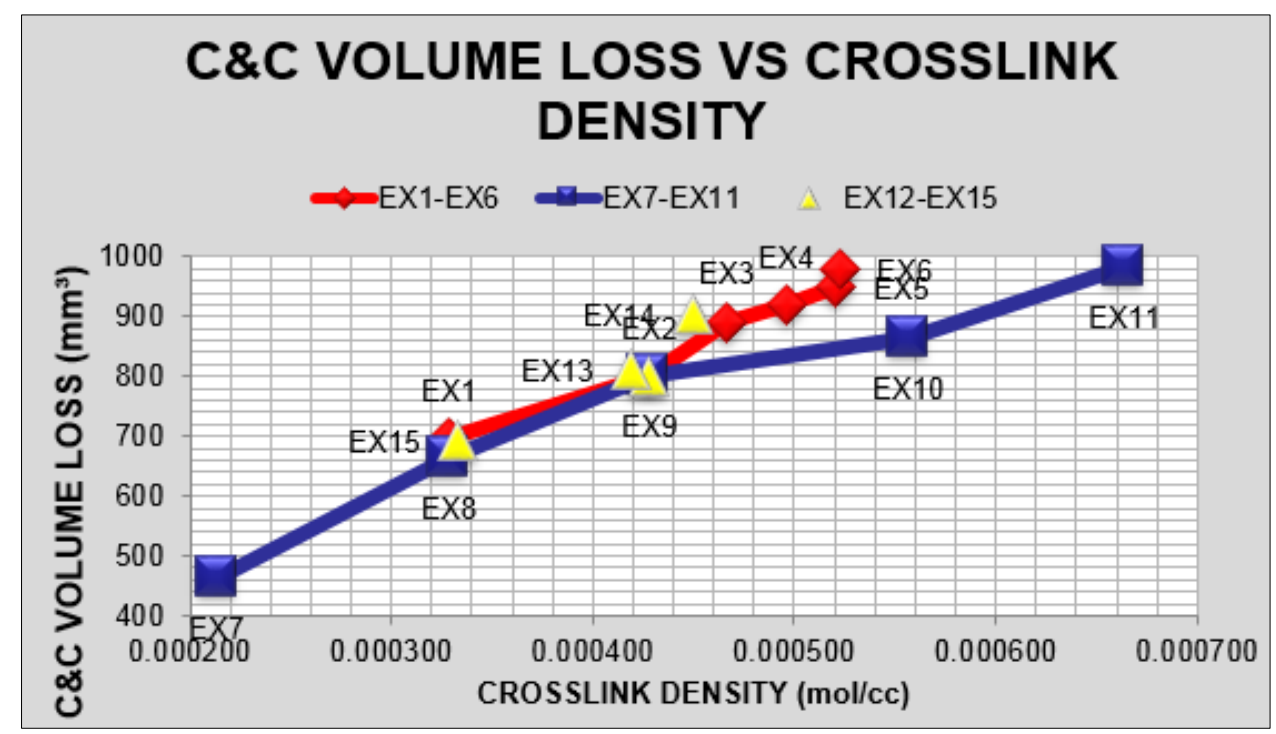

Figure 7. Comparison between $\mathrm{C} \& \mathrm{C}$ volume loss and Crosslink density

Samples from EX1-EX6 and EX7-EX11 shows gradual increase in C\&C volume loss with corresponding increase in the crosslink density. So C\&C resistance decreases with Crosslink density irrespective of whether it is effected by changing Sulphur or Accelerator. Hardener resin does not make any significant change in Crosslink density and $\mathrm{C} \& \mathrm{C}$ resistance. Replacement of process oil by process aid was increases the Crosslink density and reduces the $\mathrm{C} \& \mathrm{C}$ resistance. Replacing Gum resin by process oil shows improvement in $\mathrm{C} \& \mathrm{C}$ resistance with reduced Crosslink density.

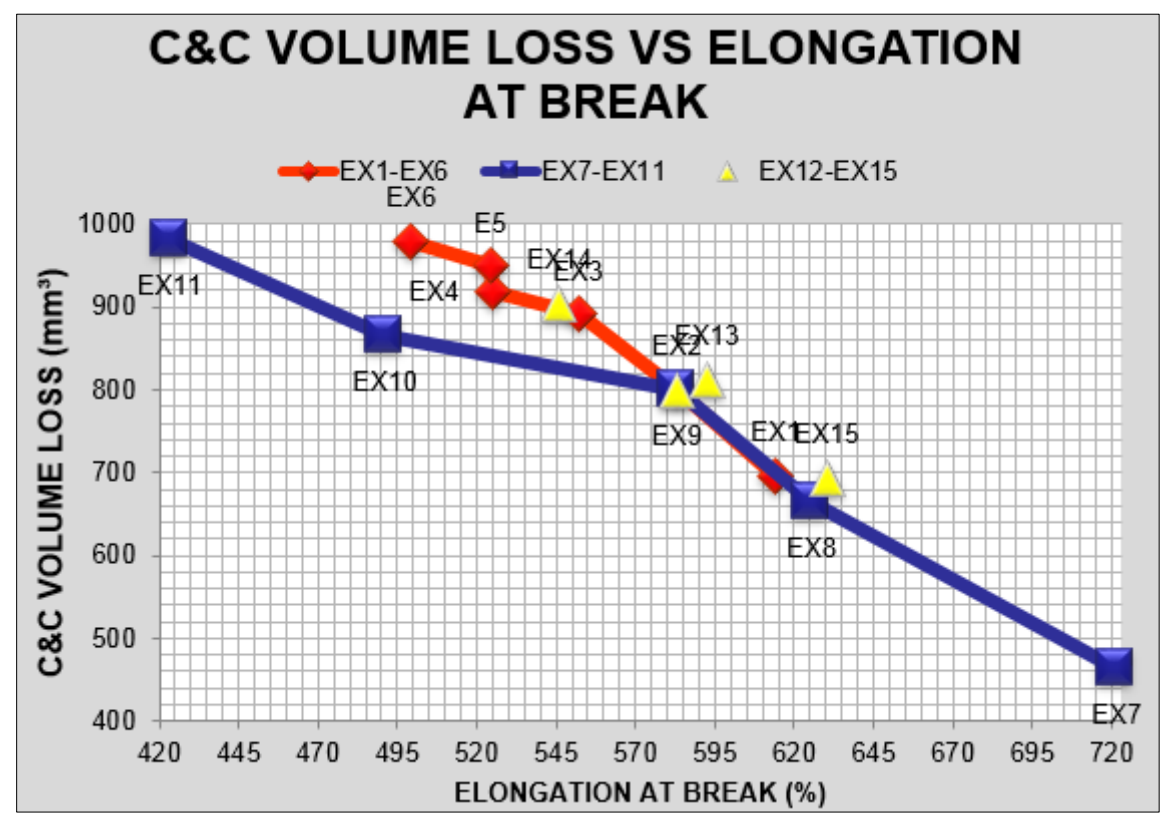

Figure 8. Comparison between C\&C volume loss and EB\%

For a better $\mathrm{C} \& \mathrm{C}$ resistance, high elongation at break achieved by reducing Sulphur is preferred as compared to reducing Accelerator. Irrespective of the input factor, $\mathrm{C} \& \mathrm{C}$ resistance improves gradually with increase in elongation at break. 


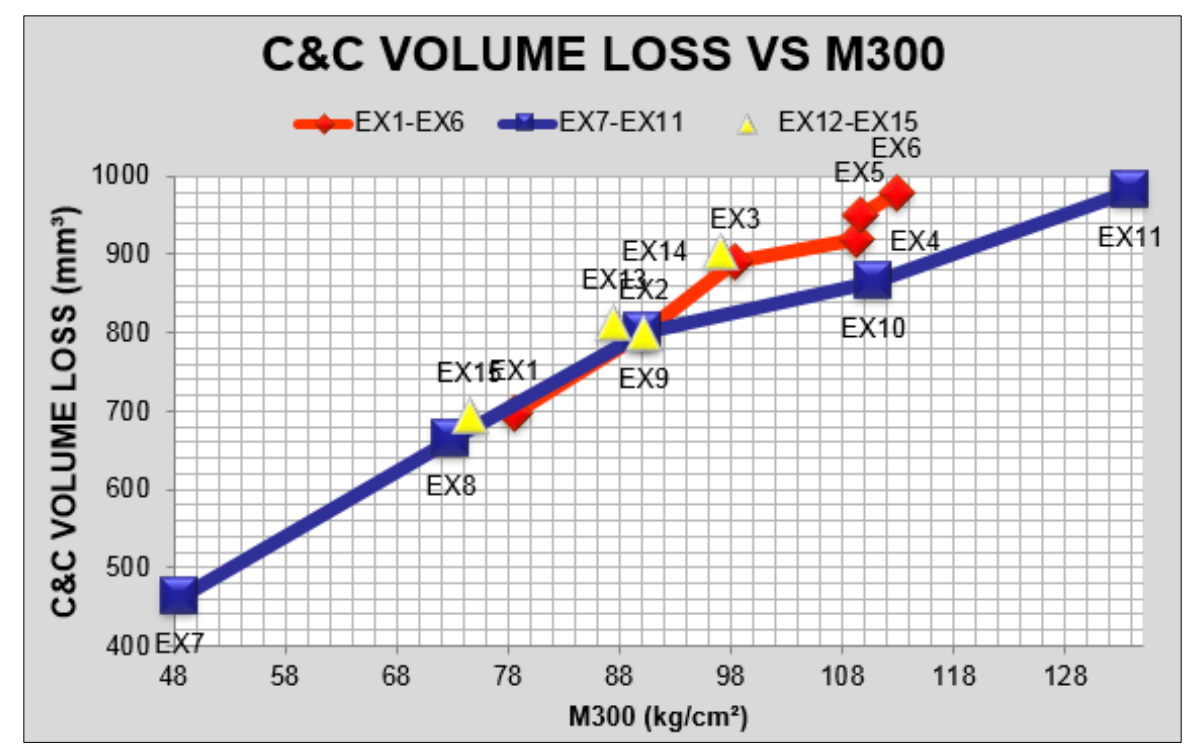

Figure 9. Comparison between $\mathrm{C} \& \mathrm{C}$ volume loss and Modulus

Irrespective of the input factor, Cut and Chip resistance improves gradually with decrease in Modulus. Ex14 having the highest modulus and lowest elongation at break shows the poor C\&C resistance. Ex15 having the lowest modulus and highest elongation at break shows the better $\mathrm{C} \& \mathrm{C}$ resistance.

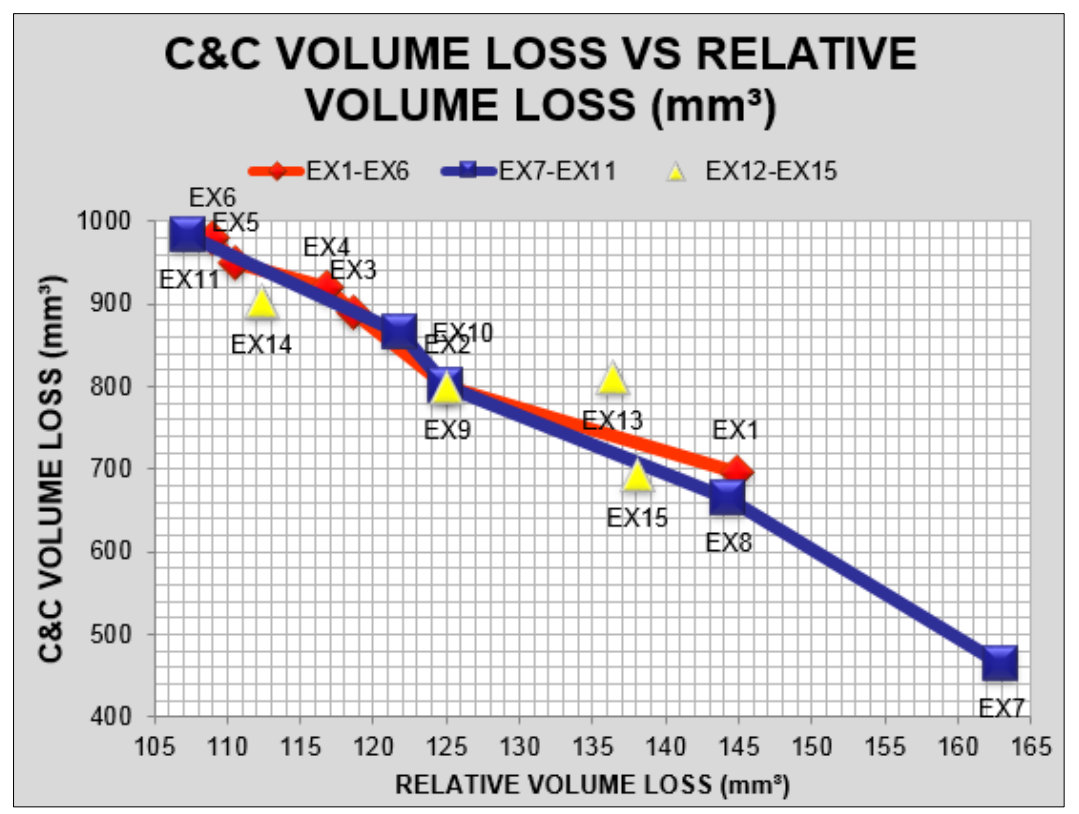

Figure 10. Comparison between $C \& C$ volume loss and relative volume loss 
Like earlier work by Shamim ahmad et al, in this study also we found there is an increasing $\mathrm{C} \& \mathrm{C}$ resistance with decreasing abrasion resistance.

\section{Conclusions}

In this study the Laboratory Cut and Chip resistance of 15 compounds were investigated. The chemical Crosslink density was also calculated and compared with the Cut and Chip resistance. The Cut and Chip resistance was also compared with the other physical properties. Based on the test results were obtained in this study, the following conclusions could be reached.

An increasing trend of cut and chip resistance was found with decreasing Crosslink density. So the $\mathrm{C} \& \mathrm{C}$ resistance and crosslink density are in indirect proportions.

Cut and chip resistance decreases with Crosslink density irrespective of whether it is effected by changing Sulphur or Accelerator.

Hardener resin does not make any significant change in Crosslink density and $\mathrm{C} \& \mathrm{C}$ resistance.

Replacement of process oil by process aid was increases the Crosslink density and reduces the $\mathrm{C} \& \mathrm{C}$ resistance.

Replacing Gum resin by process oil shows improvement in C\&C resistance with reduced Crosslink density.

For a better $\mathrm{C} \& \mathrm{C}$ resistance, high elongation at break achieved by reducing Sulphur is preferred as compared to reducing Accelerator.

Irrespective of the input factor, $\mathrm{C} \& \mathrm{C}$ resistance improves gradually with increase in elongation at break.

Irrespective of the input factor, $\mathrm{C} \& \mathrm{C}$ resistance improves gradually with decrease in Modulus.

Ex14 having the highest modulus and lowest elongation at break shows the poor C\&C resistance.

Ex15 having the lowest modulus and highest elongation at break shows the better $\mathrm{C} \& \mathrm{C}$ resistance.

Also found that the better $\mathrm{C} \& \mathrm{C}$ resistance had unsatisfactory abrasion resistance.

\section{References}

1. QI J, HERRON JR, SANSALONE KH, et al., Validation of a steady-state transport analysis for rolling treaded tires., Tire Sci Technol. 2007;35:183-208.

2. ZHENG D., Prediction of tire tread wear with FEM steady state rolling contact simulation., Tire Sci Technol, 31, 2003, 189-202.

3.BYUNG-HO PARK DONG-HO CHANG, HAN-SEOK SONG, IL-TALK JUNG AND CHOONTACK CHO., Design Concept of Tread Compound for Cutting and Chipping Resistance of Truck Tires on On/Off the Roads., Asian Journal of Chemistry, Vol. 25, No.9, 2011, pp.5208-5214.

4. CHA D. W AND H.Y. JEONG., Development of a Mode III fatigue test method and a peel test method for tire specimens., International J. Fatigue, Vol.33, 2011, pp.912-920.

5. CHANGWOON NAH, BYUNG WOOK JO AND SHINYOUNG KAANG., Cut and Chip Resistance of NR-BR Blend Compounds., Journal of Applied Polymer Science, Vol. 68, 1998, pp.1537-1541.

6.DATTA AND TEIJIN TWARON B.V., P-aramid fibers improve truck tire chunk resistance., Rubber \& Plastics News October 18, 2004.

7. DATTA, S.C. J. PIERIK AND ARNHEM., Improving Cut/Chip/Chunk Resistance by Using Sulfron 3000., Presented at the German Rubber Conference, DKT 2006, 03.-06. July, Nuremberg.

8. HAWS J. R, C. R. WILDER AND W. T. COOPER., Effect of Carbon Black Structure on Abrasion Resistance., Rubber Chemistry and Technology, Vol 42, 1969, pg 1495-6.

9. Y. KIM, J. W. PARK, D. Y. LEE, AND K. H. SEO., Correlation between the Crosslink Characteristics and Mechanical Properties of Natural Rubber Compound via Accelerators and Reinforcement., Polymers 2020, p. 14; doi:10.3390/polym12092020.

10. SHAMIM AHMAD, ZION S, LEE, STEPHEN E AND KATRENICK., Cutting and chipping resistant tread for heavy service pneumatic off-the-road tires., 1987, patent US4703079. 
11. M.S. SENTHIL KUMAR, N. MOHANA SUNDARA RAJU, P.S. SAMPATH AND L.S. JAYAKUMARI., Effects of nanomaterials on polymer composites - an expatiate view., Rev. Adv. Mater. Sci. 38, 2014, 40-54.

12. HSIEN-TANG CHIU AND PEIR-AN TSAI., Aging and Mechanical Properties of NR/BR Blends., JMEPEG, Vol.15, 2006, pp.88-94.

13.D. BORNSTEIN AND R. J. PAZUR., The sulfur reversion process in natural rubber in terms of crosslink density and crosslink density distribution., Polym. Test., vol. 88, Aug. 2020, p. 106-524, doi: 10.1016/j.polymertesting.2020.106524.

14. KAUSHIK PAL, TANYA DAS, R. RAJASEKAR, SAMIR K. PAL AND CHAPAL K. DAS., Wear Characteristics of Styrene Butadiene Rubber/Natural Rubber Blends with Varying Carbon Blacks by DIN Abrader and Mining Rock Surfaces., Journal of Applied Polymer Science, Vol.111, 2009, pp.348357.

15. KAUSHIK PAL, R. RAJASEKAR, DONG JIN KANG, ZHEN XIU ZHANG, SAMIR K. PAL, CHAPAL K. DAS AND JIN KUK KIM., Influence of carbon blacks on PBR/HSR/NR with nanosilica: Morphology and wear., Journal of Materials and Design, Vol.31, 2010, pp.1156-1164.

16.H. Z. CHU., Effect of crosslink density on solubility parameters of styrene butadiene rubber and the application in pre-screening of new potential additives., Polym. Test., 2020, p. 6

17. KAUSHIK PAL, SAMIRK.PAL, CHAPALK.DAS AND JINKUKKIM., Influence of fillers on NR/SBR/XNBR blends. Morphology and wear., Journal of Tribology International, Vol.43, 2010, pp.1542-1550.

18. KAUSHIK PAL, SAMIR K. PAL, CHAPAL K. DAS, JIN KUK KIM., Effect of fillers on morphological and wear characteristics of NR/HSR blends with E-glass fiber., Journal of Materials and Design, Vol.35, 2012, pp.863-872.

19.R. STOČEK et al., Characterisation of cut and chip behaviour for NR, SBR and BR compounds with an instrumented laboratory device., Plastics, Rubber and Composites, 2018, p. 11

DOI:10.1080/14658011.2018.1468161.

20.R. KIPSCHOLL, R. STOČEK., Quantification of chip and cut behaviour of basic rubber., RFP Rubber Fibres Plastics, 02, 2019, pp.88-91.

21.MAHAPATRA D, B. ARUN, M. BRINDHA AND K. RAVICHANDRAN., The impact of 200 series carbon black on cut \& chip resistance of solid tire tread compound - part 1., Rubber World, Vol. 232, 2005, pp. 26-33.

22.MAHAPATRA D, B. ARUN, M. BRINDHA AND K. RAVICHANDRAN., The impact of 200 series carbon black on cut \& chip resistance of solid tire tread compound - part 2', Rubber World, Vol. 232, 2005, pp. 43-45.

23.S. VISHVANATHPERUMAL, V. NAVANEETHAKRISHNAN, G. ANAND,

S. GOPALAKANNAN, Evaluation of Crosslink Density Using Material Constants of EthylenePropylene-Diene Monomer/Styrene-Butadiene Rubber with Different Nanoclay Loading: Finite Element Analysis-Simulation and Experimental., Adv. Sci. Eng. Med., vol. 12, no. 5, pp. 632-642, May 2020, doi: 10.1166/asem.2020.2567.

24. SALEESUNG THANISARARAT et al., Correlation of crosslink densities using solid state NMR and conventional techniques in peroxide-crosslinked EPDM rubber., Polymer, Vol.56, 2015, pp.309317. DOI-10.1016/j.polymer.2014.10.057

25. MANAS.D, M. MANAS, M. STANEK, V. PATA., Wear of tire treads., Journal of Achievements in Materials \& Manufacturing Engineering., Vol.37, Issue 2, 2009, pp.538-543.

26. LIANG H, FUKAHORI Y, THOMAS AG, et al., The steady state abrasion of rubber: why are the weakest rubber compounds so good in abrasion., Wear, 268, 2010, 756-762.

27. LIANG H, FUKAHORI Y, THOMAS AG, et al., Rubber abrasion at steady state., Wear., 266, 2009, 288-296.

28. GENT AN, PULFORD CTR., Mechanisms of rubber abrasion., J Appl Polym Sci., 28,1983, $943-$ 960. 
29.C. G. ROBERTSON, J. D. SUTER, M. A. BAUMAN, R. STOČEK, W. V. MARS., Finite Element Modeling and Critical Plane Analysis of a Cut-and-Chip Experiment for Rubber., Tire Sci. Technol., Feb. 2020, doi: 10.2346/tire.20.190221.

30. R. STOČEK et al., Characterizing Rubbers Resistance Against Chip and Cut Behavior., Rubber World, Jan 2018.

$\overline{\text { Manuscript received: } 19.10 .2020}$ 